\title{
Economic restructuring in Eastern Europe and acid rain abatement strategies
}

\author{
Markus Amann, Leen Hordijk, Ger Klaassen, Wolfgang \\ Schöpp and Lene Sørensen
}

Acid rain abatement strategies in Europe are currently being discussed in view of the expiration of the Helsinki Protocol on $\mathrm{SO}_{2}$ emission reduction. The changing energy situation in Eastern European countries is expected to have an influence on the deposition pattern in Europe. The paper presents a consistent energy scenario for Eastern European countries and compares optimal strategies to reduce $\mathrm{SO}_{2}$ emissions. These strategies are based on runs with the RAINS model in which environmental targets have been set based on critical loads for sulphur. The analysis shows that economic restructuring and efficiency improvements in Eastern European countries, as well as in Western Europe, may result in significantly lower sulphur abatement costs. Potential assistance to Eastern Europe to guarantee desired environmental standards in Western countries should therefore focus not only on providing emission control devices but also on the success of the economic transition process.

Keywords: Acid rain; Eastern Europe; Abatement strategy

Since the UN/ECE Convention on Long-range Transboundary Air Pollution was established in 1979 acid rain abatement policies have been carried out in Europe. Two protocols on international emission reductions have been signed under the Convention: in Helsinki, Finland in 1985 on the reduction of $\mathrm{SO}_{2}$ emissions, and in Sofia, Bulgaria in 1988 on the

Markus Amann, Ger Klaassen, Wolfgang Schöpp and Lene Sørensen are with International Institute for Applied Systems Analysis (IIASA), A-2361 Laxenburg, Austria; Leen Hordijk is with the Center for Environment Studies, Agricultural University, PO Box 9101. 6700 HB Wageningen, The Netherlands. emissions of $\mathrm{NO}_{x}$. The Helsinki Protocol calls for a $30 \%$ reduction of emissions of $\mathrm{SO}_{2}$ to be reached by 1993 based on 1980 emissions.

As 1993 approaches the Helsinki Protocol will need to be revised. Renegotiations started in 1990 and contain at least one new feature in comparison to the Helsinki Protocol: rather than a flat rate reduction, such as the $30 \%$ applicable to all countries, an effect oriented approach is being pursued. This means that environmental targets had to be established. The targets are based on the concept of critical load, which has been defined as 'a quantitative estimate of an exposure to one or more pollutants below which significant harmful effects on specified elements of the environment do not occur according to present knowledge'. ${ }^{1}$ Maps of critical loads for Europe have been produced (Hettelingh et $a l)^{2}$ and these maps are currently the basis from which effect-oriented policies are derived.

In the early 1980s, when the Helsinki Protocol was being discussed, the situation in Eastern European countries was different. The restructuring in these countries, and the move toward market oriented economies, will have consequences for the environmental situation. It is important, therefore, that the negotiations on acid rain abatement take into account these changed conditions. National energy projections originating from before 1989 are no longer valid.

This paper analyses which effects the changes in Eastern European energy policies might have on acid rain reduction policies. The analysis was carried out with the Regional Acidification INformation and Simulation (RAINS) model developed at the International Institute for Applied Systems Analysis (IIASA) in Laxenburg, Austria. A short introduction to RAINS is presented in the next section. Two different energy scenarios will then be discussed; one represents the latest available governmental energy projections for the year 2000. For most 
Eastern countries, however, these forecasts date back several years and, as mentioned above, may no longer be valid. Another scenario has therefore been developed by the authors based on a set of simple, but consistent, assumptions on the restructuring of the energy and economic systems in all Eastern European countries. Target loads for acid deposition, as selected by 10 European countries, are presented in the fourth section. Cost optimal European abatement strategies, based on these targets, are calculated with the RAINS model. The optimization results are then analysed. This section indicates the major differences which exist in the efforts that countries would have to make for acid rain abatement under the two alternative energy scenarios. Consequences for the negotiations under the Convention are shown in the final section.

\section{The RAINS model}

Since 1984 the Regional Acidification INformation and Simulation (RAINS) model has been developed at the International Institute for Applied Systems Analysis (IIASA). The model has been extensively documented in Alcamo et $a l^{3}$ and has been used in various different ways (see inter alia Hordijk, Alcamo et al and Batterman et al). ${ }^{4}$ The RAINS model focuses on acidification of Europe's natural environment and on the deposition of sulphur and nitrogen compounds that leads to acidification. The model consists of a set of submodels that cover the cause-effect chain: pollutant generation (energy scenarios, emission abatement option, costs of control), atmospheric transport and deposition, and environmental effects (forest soil, Scandinavian lakes and groundwater). The model covers the whole of Europe, including the European part of the former USSR, using a resolution of $150 \times 150 \mathrm{~km}$ for emission and atmospheric processes, and a grid system of $0.5^{\circ}$ latitude $\times 1.0^{\circ}$ longitude for environmental impacts. Pollutants included are $\mathrm{SO}_{2}, \mathrm{NO}_{x}$ and $\mathrm{NH}_{3}$.

Emission estimates of $\mathrm{SO}_{2}$ and $\mathrm{NO}_{x}$ are based on energy data, fuel characteristics and combustion conditions (Amann). ${ }^{5}$ The emissions of $\mathrm{NH}_{3}$ have been estimated based on livestock data, nitrogen fertilizer use and appropriate emission factors.

The long-range transport of these pollutants has been modelled by the EMEP (Co-operative Programme for Monitoring and Evaluation of the LongRange Transmission of Air Pollutants in Europe) atmospheric transport model. ${ }^{6}$ This model incorporates the effects of winds, precipitation and other meteorological and chemical variables. RAINS con- tains transfer matrices between countries and gridcells derived from the EMEP model.

Originally RAINS was built as a simulation model with which alternative European abatement strategies could be evaluated. An optimization model has been added that has been extensively used to derive cost optimal policies for Europe. ${ }^{7}$ The derivation of optimal policies from critical loads and target loads is currently the main use of RAINS.

\section{Energy scenarios for Europe}

\section{The official energy pathway}

For reference the official energy pathway (OEP) reflects the individual national projections of fuel consumption for the year 2000. This scenario has been compiled based on material published by the United Nations and the International Energy Agency. ${ }^{8}$ Governments submitted data to these organizations and this has been harmonized for publication. In early 199110 Western European countries provided updates of their recent energy policies to the authors, which have been incorporated into the database. In this scenario, however, information from Eastern European countries dates back to the era before the political change in 1989, and therefore reflects expectations of the former governments pursuing the policy of centralized planning.

According to these projections total primary energy demand between 1985 and the year 2000 was expected to increase by almost $30 \%$ in Eastern European countries, excluding the USSR. The fastest growth was foreseen for electricity generation from nuclear power, with an increase by a factor of five, followed by a $33 \%$ growth of natural gas consumption. Liquid $(+19 \%)$ and solid fuels $(+13 \%)$ were expected to lose market shares. Whereas final energy demand in industrial and transportation sectors average growth rates of $33 \%$ have been projected, only a $14 \%$ increase has been envisaged for private households.

Despite the fact that many Eastern European governments established the improvement of energy efficiency as a major target for their national energy policies, the projections implied a further increase of energy intensities in centrally planned economies. Industrial energy intensity was planned to increase on average by $8 \%$ from $4.50 \mathrm{PJ} /$ million deutschmarks GDP in 1985 to $4.85 \mathrm{PJ} /$ million deutschmarks GDP in 2000. The comparable level in Western European market economies in 1985 was in 1.35 $\mathrm{PJ} /$ million deutschmarks GDP. The major reasons for these large discrepancies are the bad perform- 
Economic restructuring in Eastern Europe and acid rain abatement strategies

Table 1. Energy intensities in Eastern European countries in 1985.

\begin{tabular}{llll}
\hline & $\begin{array}{l}\text { Industry } \\
\text { (PJ/million DM GDP) }\end{array}$ & $\begin{array}{l}\text { Domestic } \\
\text { (TJ/per capita per year) }\end{array}$ & $\begin{array}{l}\text { Transport } \\
(\mathbf{P J} / \text { million DM GDP) }\end{array}$ \\
Albania & 2.56 & 12 & 1.50 \\
Bulgaria & 2.52 & 22 & 1.98 \\
ĆSFR & 5.15 & 48 & 1.24 \\
GDR & 3.95 & 70 & 0.95 \\
Hungary & 2.71 & 37 & 1.26 \\
Poland & 3.44 & 40 & 0.90 \\
Romania & 7.30 & 24 & 1.66 \\
Yugoslavia & 3.99 & 10 & 1.34 \\
Average-East & 4.50 & 34 & 1.20 \\
Average-West & 1.35 & 34 & 1.07 \\
\hline
\end{tabular}

ance of existing technical equipment in the former centrally planned economies with low energy efficiencies and the industrial structure of the national economies with the focus on energy intensive heavy industries.

A similar growth trend (a further expansion of $10 \%$ ) was projected for energy consumption for transportation purposes in Eastern Europe, which was already $10 \%$ above the Western European average level in 1985. The structures are rather different, since in Eastern countries the major fraction of fuels has been used for freight transport; in Western countries private passenger traffic had higher importance. In 1985 domestic energy consumption (34 TJ per capita per year) was at equal levels in Western and Eastern Europe. For Eastern countries the forecasts projected a $10 \%$ increase for the year 2000. (See Tables 1 and 2.)

\section{The energy efficiency scenario for Eastern Europe}

The energy efficiency in Eastern Europe (EEE) scenario anticipates a transition of centrally planned economies to market economies and tries to project implications on energy efficiency. In the absence of reliable economic forecasts the scenario is based on the assumption that growth rates of GDP will follow the lines envisaged by former governments, but that major economic restructuring processes will take place, transforming industrial infrastructures from their current orientation from energy intensive heavy industry towards more advanced production processes and less energy intensive activities. Thereby, it is assumed that overall energy intensities of Eastern European countries will gradually approach average Western European levels reported for 1985.

It is not the intention of this scenario to create a realistic projection of the actual energy demand in the year 2000 in Eastern Europe. Uncertainties in the basic success and speed of transition processes to market economies are too high to allow accurate prediction. Therefore, necessary considerations on the feasibility and possible constraints, eg the availability of capital, on such transition processes are beyond the scope of this paper. Thus this scenario has to be considered as only one plausible projection for exploring the implications of energy efficiency on international emission reduction strategies.

The RAINS model is currently implemented for all European countries including the European part of the previous USSR. Work is under way to regionalize and improve the data base for this area. In this paper modifications of energy pathways are

Table 2. Official energy pathway for the year $\mathbf{2 0 0 0 .}$

\begin{tabular}{|c|c|c|c|c|c|c|c|}
\hline & \multicolumn{7}{|c|}{ Energy use per sector $(\mathrm{PJ})$ in 2000} \\
\hline & $\begin{array}{l}\text { Conversion } \\
\text { sector }^{\text {a }}\end{array}$ & $\begin{array}{l}\text { Power } \\
\text { plants }^{b}\end{array}$ & $\begin{array}{l}\text { Domestic } \\
\text { sector and } \\
\text { services }\end{array}$ & Transport & $\begin{array}{l}\text { Industrial } \\
\text { energy } \\
\text { consumption }\end{array}$ & $\begin{array}{l}\text { Non-energy } \\
\text { use of fuels }\end{array}$ & Total \\
\hline Albania & 17 & 65 & 53 & 48 & 48 & 11 & 242 \\
\hline Bulgaria & 218 & 744 & 394 & 314 & 1059 & 37 & 2766 \\
\hline ČSFR & 198 & 814 & 844 & 220 & 1185 & 134 & 3395 \\
\hline Former GDR & 153 & 1092 & 885 & 289 & 1372 & 210 & 4001 \\
\hline Hungary & 9 & 311 & 403 & 150 & 505 & 123 & 1501 \\
\hline Poland & 206 & 1401 & 1749 & 477 & 1533 & 1 & 5367 \\
\hline Romania & 247 & 618 & 680 & 481 & 1731 & 373 & 4130 \\
\hline Yugoslavia & 339 & 1252 & 430 & 261 & 743 & 262 & 3287 \\
\hline Total & 1387 & 6297 & 5438 & 2240 & 8176 & 1151 & 24689 \\
\hline
\end{tabular}

Notes: ${ }^{a}$ Includes refineries, coke production.

${ }^{\mathrm{b}}$ Includes district heat generation. 
Table 3. Energy efficiency scenario (EEE) for the year 2000 .

\begin{tabular}{|c|c|c|c|c|c|c|c|}
\hline & \multicolumn{7}{|c|}{ Energy use per sector (PJ) in 2000} \\
\hline & $\begin{array}{l}\text { Conversion } \\
\text { sector }^{\mathrm{a}}\end{array}$ & $\begin{array}{l}\text { Power } \\
\text { plants }^{b}\end{array}$ & $\begin{array}{l}\text { Domestic } \\
\text { sector and } \\
\text { services }\end{array}$ & Transport & $\begin{array}{l}\text { Industrial } \\
\text { energy } \\
\text { consumption }\end{array}$ & $\begin{array}{l}\text { Non-energy } \\
\text { use of fuels }\end{array}$ & Total \\
\hline Albania & 9 & 33 & 92 & 19 & 27 & 11 & 191 \\
\hline Bulgaria & 61 & 362 & 227 & 129 & 235 & 4 & 1018 \\
\hline CSFR & 105 & 905 & 550 & 248 & 302 & 51 & 2161 \\
\hline Former GDR & 106 & 1068 & 551 & 360 & 890 & 69 & 3044 \\
\hline Hungary & 78 & 316 & 358 & 150 & 279 & 123 & 1304 \\
\hline Poland & 156 & 1474 & 372 & 480 & 1042 & 1 & 3525 \\
\hline Romania & 136 & 925 & 805 & 218 & 923 & 241 & 3248 \\
\hline Yugoslavia & 117 & 670 & 370 & 274 & 491 & 127 & 2049 \\
\hline Total & 768 & 5753 & 3325 & 1878 & 4189 & 627 & 16540 \\
\hline
\end{tabular}

Notes: a Includes refineries, coke production.

${ }^{\mathrm{b}}$ Includes district heat generation.

restricted to Albania, Bulgaria, ČSFR, the eastern part of Germany (the former German Democratic Republic - GDR), Hungary, Poland, Romania and Yugoslavia.

To derive sectoral fuel consumption data for this scenario the following principles have been applied for final energy demand:

- A GDP growth rate equal to the increase in primary energy consumption projected in the OEP (on average $1.4 \%$ per year between 1985 and 2000).

- Energy intensity of industrial production will gradually approach the 1985 level of the average Western European market economies. Since this process requires substantial efficiency improvements from 4.50 to $1.35 \mathrm{PJ} / \mathrm{million}$ deutschmarks GDP, which can only be accomplished through major structural changes of the industry, it is assumed in this scenario that by the year 2000 only half of the necessary changes in infrastructure will be implemented. Consequently, the energy intensity will be between the individual 1985 and the envisaged level. This decline will be achieved partly by efficiency improvements of new production and combustion plants, and partly by restructuring the national economies towards less energy intensive products with higher competitiveness on the world market.

- Domestic energy consumption, on a per capita basis, will reach the 1985 level of Western Europe.

- Fuel demand for transport, per unit of GDP, will also adapt to the average value of Western market economies.

For energy supply the following assumptions have been made:
The efficiency of thermal electricity generation will increase to $40 \%$.

- If the assumptions above allow a decline of energy input, fuels with the highest $\mathrm{CO}_{2}$ emissions will be the first to be phased out.

- In case of increasing energy demand, mainly in the transportation sector, additional consumption is supplied by fossil fuels with the lowest $\mathrm{CO}_{2}$ emissions.

As shown in Table 3 the assumptions described result in a drastically changed pattern of energy demand. The largest cut in energy consumption occurs in the industrial sector of the eight Eastern European countries excluding the former USSR, in which fuel demand drops by $32 \%$ compared to 1985 instead of the $33 \%$ increase projected by the official energy pathway. Total primary energy consumption is $25 \%$ below the 1985 level. Increasing GDP causes a $14 \%$ rise in energy use for transport purposes, whereas domestic energy consumption is $31 \%$ lower than in 1985.

The priority on phasing out fuels with highest $\mathrm{CO}_{2}$ emissions first results in a $68 \%$ cut in brown coal consumption; the total demand for solid fuels drops by $54 \%$ and use of liquid fuels decreases by approximately $30 \%$. A detailed description of the energy efficiency scenario for Eastern Europe can be found in Amann and Sørensen. ${ }^{9}$

\section{$\mathrm{SO}_{2}$ and $\mathrm{CO}_{2}$ emissions}

Since energy combustion is a major source for a number of anthropogenic emissions to the atmosphere, modifications in energy consumption will have an impact on national emission levels. The availability of various emissions control technologies does not allow derivation of national emission data directly from fuel consumption data, since actual 
Table 4. Sulphur emissions (in $\mathrm{kt} \mathrm{SO}_{2}$ ) for Eastern European countries for 1985 and the two energy scenarios.

\begin{tabular}{|c|c|c|c|c|c|}
\hline & \multicolumn{5}{|c|}{$\mathrm{SO}_{2}$ emissions (kt) } \\
\hline & \multicolumn{3}{|c|}{ OEP scenario 2000} & \multicolumn{2}{|c|}{ EEE scenario 2000} \\
\hline & 1985 & Unabated & $\begin{array}{l}\text { Maximum } \\
\text { abatement }\end{array}$ & Unabated & $\begin{array}{l}\text { Maximum } \\
\text { abatement }\end{array}$ \\
\hline Albania & 121 & 167 & 41 & 78 & 38 \\
\hline Bulgaria & 1070 & 1555 & 236 & 152 & 11 \\
\hline ČSFR & 3150 & 2513 & 708 & 1743 & 114 \\
\hline Former GDR & 5360 & 5048 & 1158 & 3892 & 431 \\
\hline Hungary & 1404 & 1529 & 580 & 1018 & 128 \\
\hline Poland & 4300 & 4165 & 749 & 3427 & 425 \\
\hline Romania & 1800 & 3261 & 313 & 2544 & 232 \\
\hline Yugoslavia & 1500 & 2393 & 321 & 1093 & 124 \\
\hline Total & 18705 & 20631 & 4106 & 13947 & 1503 \\
\hline Change & - & $+10 \%$ & $-78 \%$ & $-25 \%$ & $-93 \%$ \\
\hline
\end{tabular}

emission levels are also strongly determined by the extent of application of such technological abatement options. Table 4 displays the two extreme levels of $\mathrm{SO}_{2}$ emissions for each scenario:

The no control case, in which no emission reduction measures are applied to fuel combustion, indicates the upper range of emissions.

- The maximum feasible reduction case explores the level of remaining emissions after application of all currently available emission control technologies.

The phase out of fuels with highest specific $\mathrm{CO}_{2}$ emissions also decreases $\mathrm{SO}_{2}$ emissions. If no additional abatement efforts were taken, $\mathrm{SO}_{2}$ emissions of the energy efficiency scenario would be $25 \%$ below the level of the OEP. The maximum achievable reductions, which are important to answer questions on the feasibility of achieving critical loads, would be $93 \%$ instead of $78 \%$. In the same way, energy efficiency improvement would have a positive impact on $\mathrm{CO}_{2}$ emissions: instead of a $17 \%$ increase in the OEP scenario, Eastern Europe $\mathrm{CO}_{2}$ emissions decline by $23 \%$ compared with 1985 (see Table 5).

\section{The costs of emission reductions}

The RAINS model contains a submodule to estimate national emission control costs for any energy consumption scenario. ${ }^{10}$ This evaluation takes into account the most relevant emission control technologies for reducing $\mathrm{SO}_{2}$ and $\mathrm{NO}_{x}$ emissions ie use of low sulphur fuels, combustion modification, flue gas desulphurization and denitrification etc, and determines the cost of application under country specific conditions. Energy conservation and fuel substitution are excluded from the economic analysis.

These technology and country specific cost estimates can be combined with data on energy con- sumption into national cost curves of emission reduction to display the overall national costs to achieve certain levels of emission reductions. If cost effectiveness is taken as a criterion, curves representing increasing marginal and total costs for increasing levels of emission reductions can be easily derived. As indicated above, the shapes of such cost curves are rather sensitive to modifications in energy consumption structures. Consequently, major differences have to be expected between the cost curves for the official energy pathway (OEP) and the energy efficiency case (EEE).

To illustrate the sensitivity of such cost curves an example for the ČSFR is displayed in Figure 1. For each scenario the figure shows the level of unabated emissions (the lower end of the cost curves with zero abatement costs) and indicates the increase of emission control costs for decreasing remaining emissions. Abatement costs are displayed as total annual cost (million deutschmarks per year) required to achieve the desired level of remaining emissions.

The reduction in energy consumption results in a considerable lower level of the Czechoslovakian $\mathrm{SO}_{2}$ emissions even in the absence of any emission control measures. Instead of $2513 \mathrm{kt}$ of $\mathrm{SO}_{2}$ only $1743 \mathrm{kt}$

Table 5. $\mathrm{CO}_{2}$ emissions (in $\mathrm{Mt} \mathrm{CO}_{2}$ ) for the Eastern European countries, excluding the USSR, for 1985 and two energy scenarios.

\begin{tabular}{lccc}
\hline & \multicolumn{2}{c}{$\mathbf{C O}_{2}$ emissions (Mt) } & \\
& $\mathbf{1 9 8 5}$ & OEP scenario & EEE scenario \\
Brown coal & 628 & 709 & 449 \\
Hard coal & 336 & 397 & 267 \\
Coke, briquettes & 100 & 103 & 20 \\
Gasoil, diesel & 100 & 128 & 99 \\
Heavy fuel oil & 133 & 134 & 88 \\
Gasoline & 105 & 139 & 83 \\
Natural gas & 169 & 226 & 211 \\
Total & 1571 & 1836 & 1217 \\
Change & - & $+17 \%$ & $-23 \%$ \\
\hline
\end{tabular}




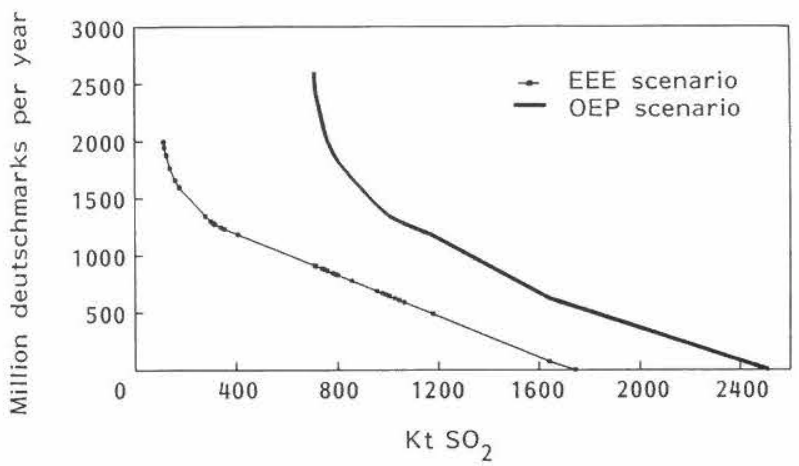

Figure 1. Cost curves of $\mathrm{SO}_{2}$ reduction in the ČSFR.

would be emitted in a no control case. Application of abatement technologies enables minimum emissions to be feasible at a drastically lower level. The large amount of lignite combustion in the OEP case limits the minimum emission level to $78 \%$ reduction in comparison to 1980 , whereas the phase out of this fuel in the EEE scenario enables a $96 \%$ decline. In addition, significantly lower funds are required for reductions of $\mathrm{SO}_{2}$ if energy efficiency is improved. For example, a $50 \%$ reduction from the 1980 levels would be a free side effect of the EEE scenario, whereas in the OEP case some 800 million deutschmarks per year would be required. In the same way, in the EEE case a $78 \%$ reduction would only cost some $30 \%$ of the amount necessary in the OEP scenario.

\section{Target loads for acid deposition in Europe}

Critical loads reflect the maximum input of acid deposition which can be tolerated by sensitive ecosystems without environmental damage. In 1990 the first estimate of critical loads for acid deposition was established, with international cooperation, for the whole of Europe and has been published in Hettelingh et al. ${ }^{11}$ If the achievement of these critical loads is taken as a target for international environmental policy, substantial emission reductions are required over large regions of Europe with zero emission levels in some countries (Amann et al). ${ }^{12}$ Thus critical loads are not considered as short-term policy targets; interim target loads have been introduced to establish a goal for the upcoming negotiations on the next sulphur protocol in Europe.

Presently, target loads for acid deposition have been specified by 10 European countries (Table 6). In some cases these intermediate target loads have been derived through specification of a certain fraction of the ecosystems to be protected, in other cases by balancing estimates of environmental damange and expected emission abatement costs. In order to derive targets for sulphur deposition, provisions had to be made to account for deposition and uptake of base cations. Target loads used in this paper are listed in Table 6.

\section{Scenario analysis}

The RAINS model has been used to derive the cost

Table 6. National target loads used in this paper.

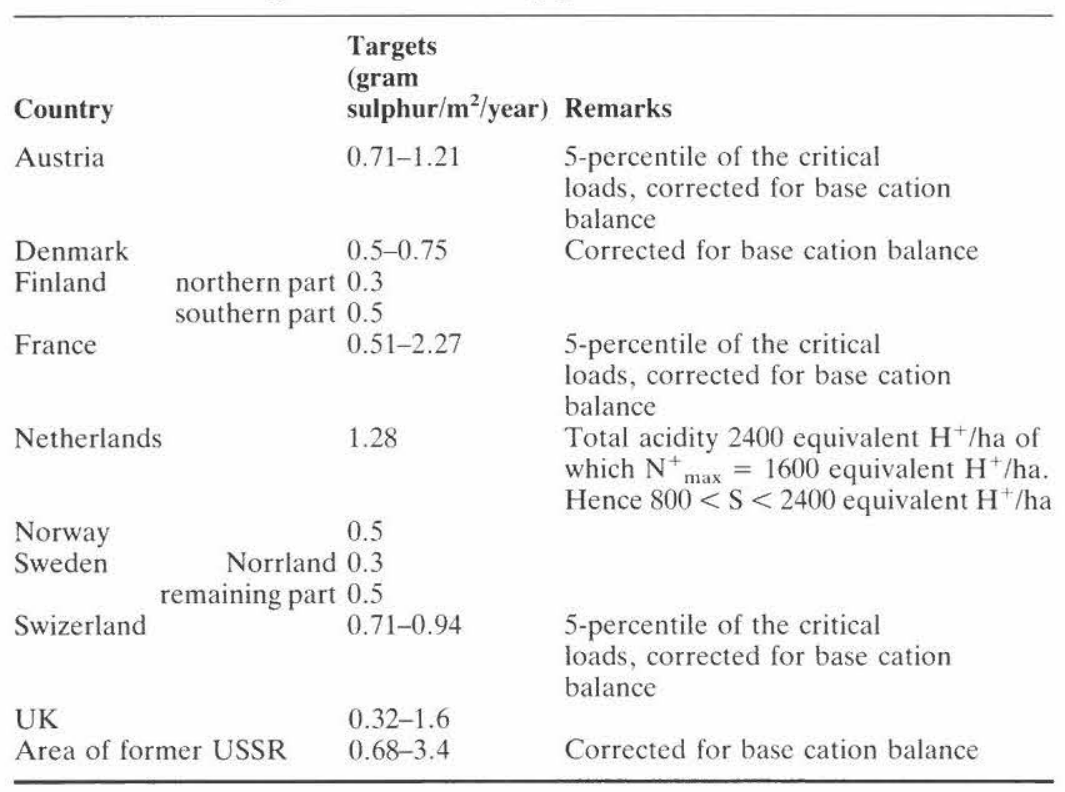




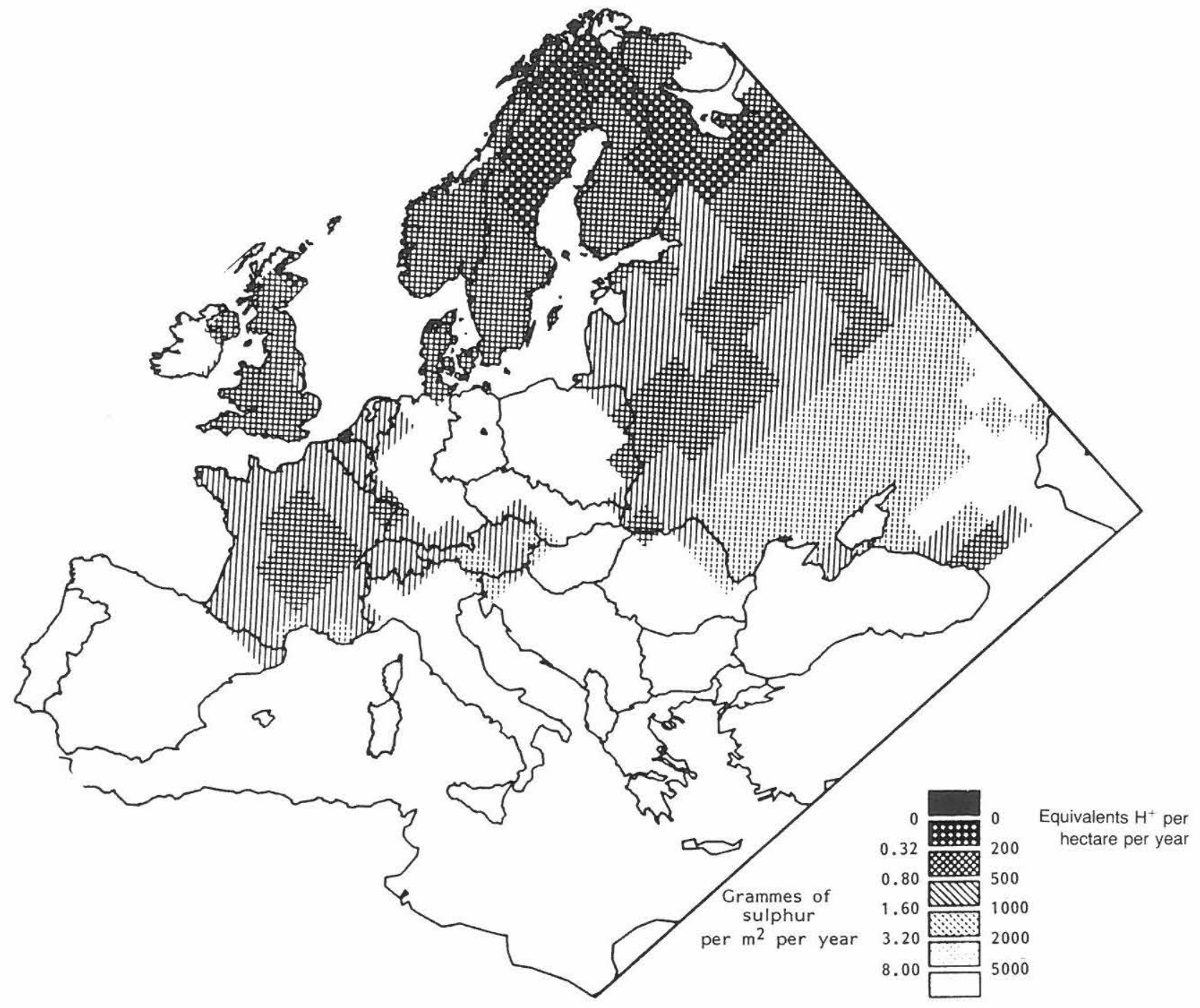

Figure 2. Map of (interim) targets loads for sulphur deposition in Europe.

Source: Country submissions to Coordinating Center for Effects, RIVM, Netherlands, 1991.

minimal international allocation of emission reductions to achieve specified target loads for sulphur deposition. The optimization procedure takes into account the spatial distribution of the target loads, the country specific costs of emission reductions and the atmospheric linkages of long-range transport of sulphur between the emission sources, and the receptor sites for which target loads have been established. Details on the RAINS optimization module can be found in Shaw et al. ${ }^{13}$

The costs and emission reductions required to achieve the target loads in the year 2000 are presented in Tables 7-9 for both energy scenarios: for the official energy pathway (OEP) and for the efficiency improvement scenario for Eastern Europe (EEE). Resulting reduction levels are compared with the emission projections for the year 2000 as they are envisaged by the individual governments based on the national legislation (the current reduction plans). ${ }^{14}$

Both scenarios, as shown in Tables 7 and 8 , imply an overall emissions reduction of approximately $72 \%$ over the 1980 emissions, which is more than twice as high as the current commitments. The highest reductions are necessary in north-western Europe where the specified target loads are close to the minimum deposition level achievable through application of all available emission control technologies eg in Belgium, Denmark, Finland, Germany, Netherlands, Sweden and the UK. The tight target loads in this region require high reductions almost irrespective of involved costs of abatement. Consequently, between the two scenarios no major differences occur for these countries. 
Table 7. Comparison of $\mathrm{SO}_{2}$ emissions and abatement costs.

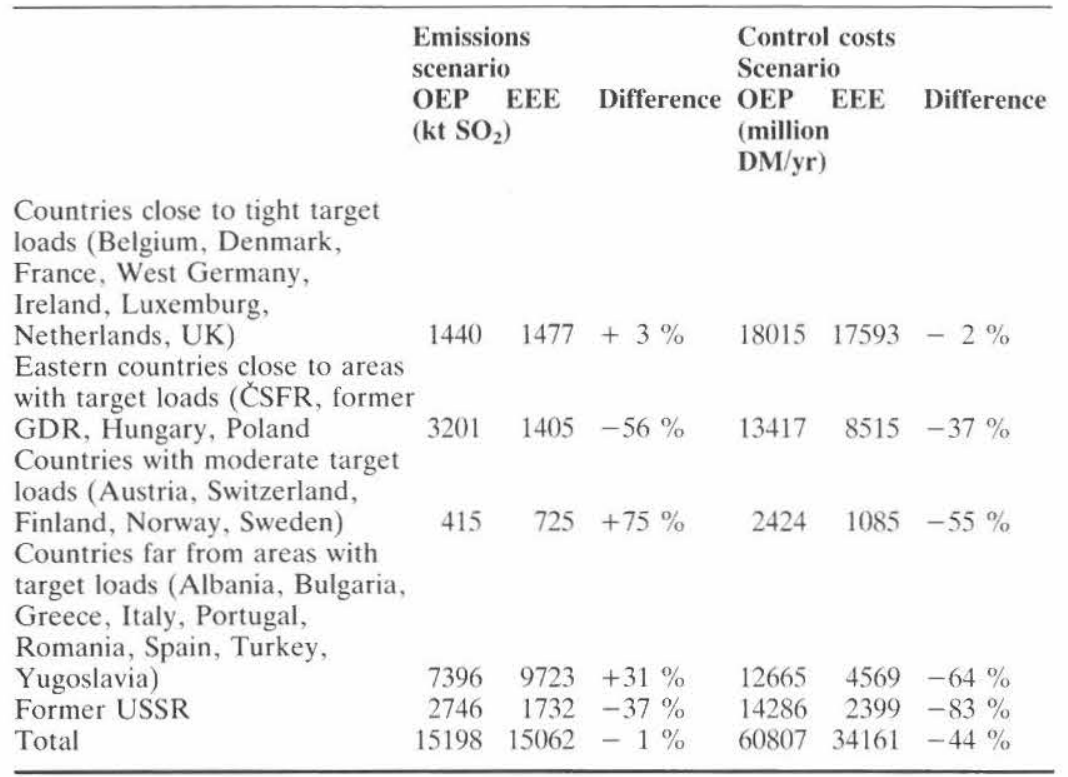

Large differences, however, can be observed for Eastern European countries whose emissions have substantial impact on acid deposition in areas with target loads (ČSFR, East Germany, Hungary, Poland and the former USSR). An optimization based on the EEE scenario determines significantly lower remaining emissions than in the OEP case in which no energy efficiency improvements are assumed. Although the required percentage reduction levels are higher in the case of the EEE scenario, (ČSFR

Table 8. Emission and percentage reductions for year $2000(C R P=$ current reduction plans; negative numbers indicate an increase of emissions).

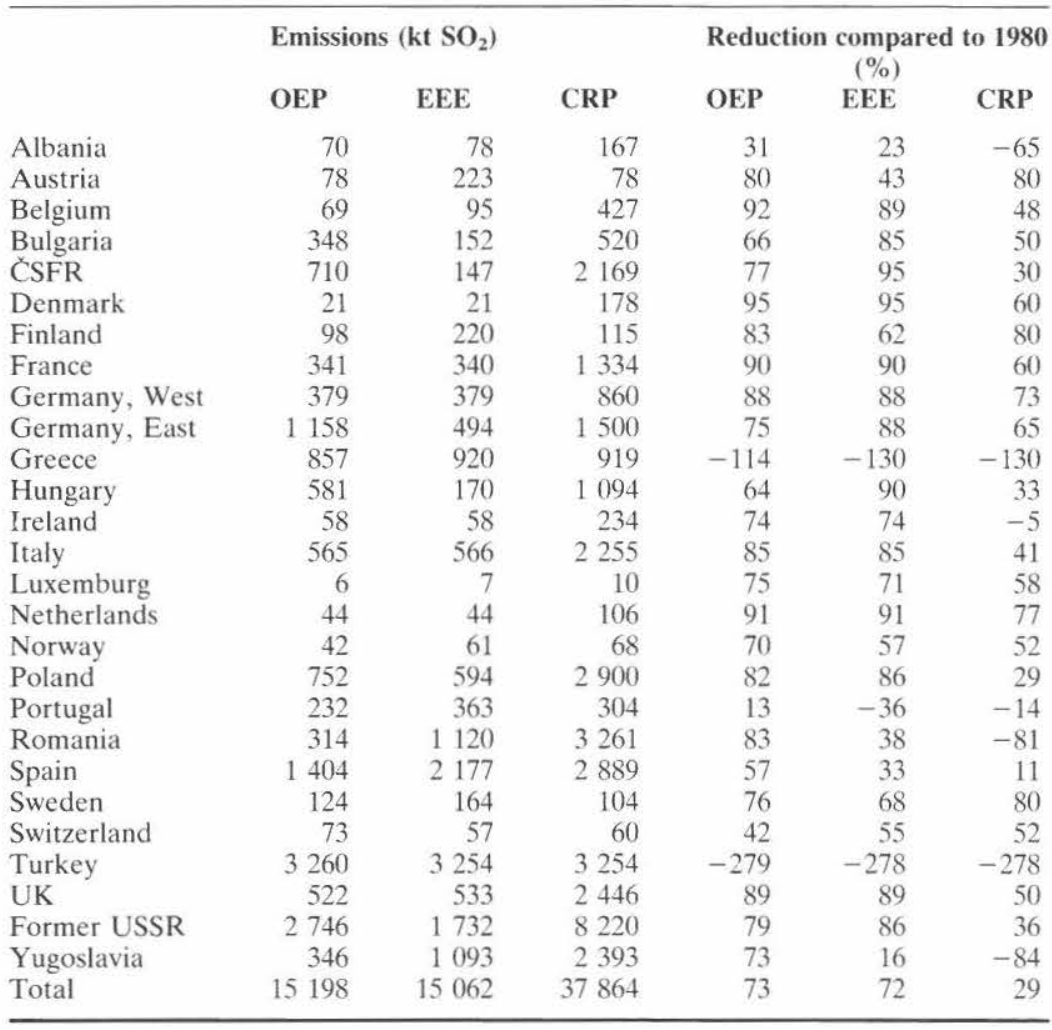


Table 9. $\mathrm{SO}_{2}$ abatement costs in the year 2000 .

\begin{tabular}{|c|c|c|c|c|c|c|}
\hline & \multicolumn{3}{|c|}{$\begin{array}{l}\text { Abatement costs (million } \\
\text { DM/year) }\end{array}$} & \multicolumn{3}{|c|}{$\begin{array}{l}\text { Costs as percentage of GDP } \\
(\%)\end{array}$} \\
\hline & OEP & EEE & CRP & OEP & EEE & CRP \\
\hline Albania & 90 & 0 & 0 & 0.64 & 0.00 & 0.00 \\
\hline Austria & 651 & 210 & 658 & 0.26 & 0.08 & 0.26 \\
\hline Belgium & 1554 & 1216 & 152 & 0.44 & 0.34 & 0.04 \\
\hline Bulgaria & 1293 & 0 & 1046 & 1.07 & 0.00 & 0.86 \\
\hline CSFR & 2541 & 1711 & 281 & 1.10 & 0.74 & 0.12 \\
\hline Denmark & 743 & 747 & 88 & 0.28 & 0.29 & 0.03 \\
\hline Finland & 934 & 297 & 181 & 0.37 & 0.12 & 0.07 \\
\hline France & 2105 & 2111 & 0 & 0.09 & 0.09 & 0.00 \\
\hline Germany, West & 6725 & 6749 & 3627 & 0.25 & 0.26 & 0.14 \\
\hline Germany, East & 4515 & 2815 & 750 & 1.34 & 0.84 & 0.22 \\
\hline Greece & 50 & 0 & 0 & 0.03 & 0.00 & 0.00 \\
\hline Hungary & 892 & 475 & 198 & 0.64 & 0.34 & 0.14 \\
\hline Ireland & 282 & 282 & 0 & 0.34 & 0.34 & 0.22 \\
\hline Italy & 2979 & 2987 & 600 & 0.16 & 0.16 & 0.00 \\
\hline Luxemburg & 29 & 16 & 4 & 0.19 & 0.11 & 0.03 \\
\hline Netherlands & 892 & 893 & 539 & 0.16 & 0.16 & 0.09 \\
\hline Norway & 166 & 92 & 77 & 0.07 & 0.04 & 0.03 \\
\hline Poland & 5469 & 3514 & 1375 & 1.22 & 0.78 & 0.31 \\
\hline Portugal & 134 & 0 & 53 & 0.12 & 0.00 & 0.10 \\
\hline Romania & 3481 & 1158 & 0 & 1.70 & 0.56 & 0.00 \\
\hline Spain & 988 & 424 & 195 & 0.13 & 0.06 & 0.03 \\
\hline Sweden & 660 & 429 & 385 & 0.16 & 0.11 & 0.10 \\
\hline Switzerland & 13 & 57 & 44 & 0.00 & 0.02 & 0.01 \\
\hline Turkey & 0 & 0 & 0 & 0.00 & 0.00 & 0.00 \\
\hline UK & 5685 & 5579 & 1453 & 0.30 & 0.30 & 0.08 \\
\hline Former USSR & 14286 & 2399 & 4790 & 0.50 & 0.08 & 0.17 \\
\hline Yugoslavia & 3650 & 0 & 0 & 1.98 & 0.00 & 0.00 \\
\hline Total & 60807 & 34161 & 16496 & 0.35 & 0.19 & 0.09 \\
\hline
\end{tabular}

$95 \%$ instead of $77 \%$, East Germany $88 \%$ instead of $75 \%$, Hungary $90 \%$ instead of $64 \%$, Poland $86 \%$ instead of $82 \%$ etc) absolute sulphur removal, through control technologies, is substantially lower due to the low baseline emissions caused by less energy consumption. Compare the emission levels in Table 8 with the unabated levels in Table 4: in ČSFR $1326 \mathrm{kt} \mathrm{SO}$ are removed instead of $1803 \mathrm{kt}$, in East Germany 3400 kt instead of 4040 kt, in Poland 2830 kt instead of $3140 \mathrm{kt}$ etc. Consequently, removal costs are lower in ČSFR, East Germany and Poland by some $25 \%$ and in Hungary by $46 \%$.

Larger differences occur for countries which do not have close atmospheric connection to areas protected by target loads ie Portugal, Spain, Romania, Yugoslavia etc. This is caused by the high amount of brown coal combustion in the OEP case in Eastern Europe (ČSFR, Hungary, Poland) which limits the maximum sulphur removal at sources close to the areas with target loads. In this scenario desired reductions in sulphur deposition to achieve the target loads cannot therefore be attained entirely through measures at close sources. Instead, these have to be achieved by controlling distant emitters eg by reducing Yugoslavian emissions by $71 \%$ and Romania's emissions by $81 \%$. Since in the energy efficiency (EEE) case lower emission levels can be attained in the Eastern key countries (for example in Poland, ČSFR, East Germany and Hungary), the necessity to control distant sources no longer exists. Thereby, reduction levels decline for Yugoslavia to $8 \%$ and to $33 \%$ for Romania. Not surprisingly, the cost saving in these countries is substantial.

Higher emission reductions in Eastern countries in the EEE scenario do also relax abatement requirements for some Western countries. For example, through efficiency improvements in Eastern Europe, Austrian $\mathrm{SO}_{2}$ emissions have only to decline by $32 \%$ instead of $80 \%$ in the OEP case. Costs in Austria thereby decline by $68 \%$, although no assumptions for the Austrian energy system have been modified; the energy efficiency improvements apply only to Eastern countries. This effect is significant also in other countries who have specified target loads for their own territory, for example in Finland, Norway and Sweden. In total, these four countries save 55\% of their emission control costs.

Although this cost saving effect applies to the majority of countries, it cannot be generalized. In contrast to the cases mentioned the efficiency improvements in Eastern countries require an increase of reduction efforts in Switzerland, although Switzerland is relatively far from these Eastern countries. To explain this phenomenon it is neces- 
sary to recall the relaxation of reduction requirements for distant countries such as Yugoslavia, Romania and also Spain and Portugal, which was made possible through additional control in Eastern countries relatively close to the tight target loads in Scandinavia, for example in Poland and East Germany. These additional reductions in the Eastern countries do satisfy the Nordic requirements, but do not fully compensate the increase of sulphur deposition at the Swiss target areas caused by higher emissions in Southern Europe. Therefore, the deficit in Switzerland can be covered most efficiently by higher emission reductions in Switzerland itself.

\section{Conclusions}

A possible approach of the energy intensities of former centrally planned economies to typical Western Europe values will result in considerably lower energy consumption in Eastern Europe. Such a decline of energy consumption will presumably have favourable impacts on the competitiveness of national economies. Furthermore, a substantial improvement in the environmental situation can be expected.

\section{Impacts for Eastern Europe}

The energy efficiency scenario developed assumes a major restructuring process in Eastern European countries to structures comparable with Western market economies. The implied decline of heavy industry results in a trend of decreasing energy intensities to the average level observed in Western Europe. If a partial restructuring is assumed to be achieved by the year 2000 , total primary energy consumption declines by $25 \%$ between 1985 and the year 2000. This cut in energy consumption and related restructuring of energy supply systems leads to $\mathrm{CO}_{2}$ emissions $23 \%$ below the 1985 level; $\mathrm{SO}_{2}$ emissions would be $25 \%$ lower if no technological abatement measures were taken.

Such a change in the energy consumption structure not only has impacts on the level of unabated $\mathrm{CO}_{2}$ and $\mathrm{SO}_{2}$ emissions, but also on costs required to control remaining emissions. For all the countries analysed national emission control costs to achieve certain levels of emission reductions are substantially lower if energy efficiency improvements are assumed. As an example, to achieve specified target loads for sulphur deposition Eastern Europe would have to spend some 20 billion deutschmarks per year less for abatement of sulphur emissions if energy efficiency were improved.

The full costs and benefits of structural changes are difficult to estimate. However, the cost savings derived can be taken as indicators to determine the cost-effectiveness of possible measures to improve energy efficiency. Since these numbers only take into account the benefits for $\mathrm{SO}_{2}$ reduction, it has to be kept in mind that energy efficiency improvements often have other positive impacts which are not quantified in this analysis, for example on the trade balance, employment, exploitation of nonrenewable resources etc.

\section{Implications for strategies to achieve target loads}

According to the critical/target loads concept emissions should be reduced until acceptable regional levels of deposition are achieved ie the critical or target loads. Necessary emission reductions can be internationally allocated aiming at an international cost minimum. However, such optimization results are sensitive to modified assumptions on emission control costs. As indicated, changes in energy consumption forecasts do have an influence on estimated emission reduction costs. Consequently, the optimization procedure results in different abatement schedules for each of the energy scenarios.

As demonstrated, efficiency improvements do not only lead to lower abatement costs within the country in which relevant measures are actually implemented. Through the international optimization approach such changes might also have positive impacts on control efforts required from other countries. As presented in Table 7 the lower energy consumption requires a European total of $44 \%$ below the costs of the reference case. In Eastern Europe, in which the changes are assumed, a $37 \%$ cost saving occurs, whereas in Western countries with moderate target loads costs are $55 \%$ lower.

The achievement of selected target loads in Western Europe, which are often related to accepted levels of environmental damage, crucially depends on the willingness of all European countries to implement the required reductions. If countries drop out of the optimized abatement schedule, others have to compensate for the lacking reductions:

If countries do not participate in the cooperative effort, the Europe wide cost minimum solution can only be maintained by an international transfer of funds to implement the necessary measures at the optimal places.

- If such transfers did not take place and some of the 'optimal' measures were not implemented, target loads can only be maintained if other countries compensate lacking reductions by additional control at other places eg within 
their own territory). Total European abatement costs are therefore necessarily higher since the cost optimality principle is violated.

In either case ie transferring funds or transferring abatement measures, the donor countries will face additional costs over and above those initially allocated for domestic measures.

\section{Implications for possible assistance for Eastern Europe}

Currently specified target loads put high demands for emission reductions not only on countries in Western and Northern Europe, who have established target loads for their own territory, but also on countries in economic transition processes who have not yet announced target loads.

According to the optimization results based on the OEP scenario the majority of resources have to be spent in countries without target loads for their own territory. Furthermore, caused by the comparatively low economic performance in Eastern Europe, burdens posed on these national economies, expressed as percentage of the GDP required for emission control measures, are in many cases much higher than in Western Europe (see Table 9). In many Eastern European economies between 1.0 and 2.0\% of their GDP would be required to reduce emissions, whereas the European average, including these Eastern countries, is only at $0.35 \%$ of the GDP. However, at present all these demands are mainly caused by the established target loads in Western Europe. In order to encourage the implementation of the suggested measures in Eastern countries, and thereby guarantee the cost optimal achievement of the Western target loads, it might be in their own interest if the West assisted Eastern countries to achieve required reductions. It is important to state that any financial support for Eastern countries has to be on top of the measures specified in the OEP scenario for measures in the West.

If, however, the energy efficiency scenario is taken as a basis, abatement efforts in Eastern countries are significantly lower. Burdens to Eastern economies range in most cases between 0.3 and $0.8 \%$ of the GDP (instead of 1.0 to $2.0 \%$ in the OEP case). The improvement of energy efficiency in Eastern Europe allows also the West to considerably decrease its own abatement efforts even if no assistance to the East is considered. Consequently, it should be in the vital self interest of the West to ensure the success of the restructuring process.

The considerable cost saving potential for the West might motivate Western countries to explore the possibilities of promoting the success of the restructuring process. In contrast to the OEP case, assistance has not only to ensure the proper installation of emission control devices, but must also guarantee the timely accomplishment of the structural changes in the economy leading to the increase of energy efficiency.

If such assistance were to materialize in financial support for Eastern Europe, Western countries could utilize at least the difference in their abatement costs of the OEP and EEE scenarios to trigger the necessary processes in the East, and still show a cost saving compared to the OEP case. If financial transfers in the OEP case are assumed to be necessary, the benefits would be even larger. Furthermore, as indicated, a number of other positive impacts would be accomplished through this strategy as free side effects, ie the decline of $\mathrm{CO}_{2}$ emissions and economic improvements.

Although these conclusions suggest priority be given to the implementation of the economic restructuring process it has to be stressed that in both scenarios the efficient control of emissions of large combustion plants is an absolute necessity. The only difference, however, is that in the case of energy efficiency fewer large boilers will be operated and therefore fewer emissions have to be reduced. Strategies currently focusing on, for example, the desulphurization of the largest emitters in Eastern Europe, would keep their validity as long as the basic principles of energy efficiency improvements were followed.

It should also be stressed that the magnitude of efficiency improvements necessary to approach Western European levels can not only be achieved by application of more advanced combustion technologies; the larger part, however, would be contributed through structural changes of the economies towards less energy intensive industrial activities.

It should be mentioned that although a number of assumptions have been made for deriving actual numbers of the energy efficiency scenarios, the main conclusions derived are robust in respect to modifications of these assumptions.

${ }^{1}$ J. Nilsson and P. Grennfelt, Critical Loads for Sulphur and Nitrogen, Miljorapport No 15, Nordic Council of Ministers, Copenhagen, Denmark, 1988.

${ }^{2}$ J.-P. Hettelingh, R.J. Downing and P.A.M. de Smet, eds, Mapping Critical Loads for Europe, UN-ECE Coordination Center for Effects Technical Report No. 1, National Institute for Public Health and Environmental Protection, Bilthoven, Netherlands, 1991.

${ }^{3}$ J. Alcamo, V.R.W. Shaw and L. Hordijk, The RAINS Model of Acidification: Science and Strategies in Europe, Kluwer Academic Publishers, Dordrecht, 1990.

${ }^{4} \mathrm{~L}$. Hordijk, 'Towards a targeted emission reduction in Europe', 
Atmospheric Environment, Vol 20, 1986, pp 2053-2058; J. Alcamo, M. Amann, J.-P. Hettelingh, M. Holmberg, L. Hordijk, J. Kämäri, L. Kauppi, P. Kauppi, G. Kornai and A. Mäkelä, 'Acidification in Europe: a simulation model for evaluating control strategies', $A M B I O$, Vol 16, 1987, pp 232-245; S.A. Batterman, M. Amann, J.-P. Hettlingh, L. Hordijk and G. Kornai, 'Optimal $\mathrm{SO}_{2}$ abatement policies in Europe: some examples', Systems Analysis - Modelling - Simulation, Vol 5, 1988, pp 533-559.

${ }^{5} \mathrm{M}$. Amann, 'Energy use, emissions and abatement costs', in $o p$ cit, Ref 3, pp 61-102.

${ }^{6} \mathrm{~A}$. Eliassen and J. Saltbones, 'Modelling of long-range transport of sulphur over Europe: a two year model run and some model experiments', Atmospheric Environment, Vol 17, 1983, pp 14571473; T. Iversen, N. Halvorsen, S. Mylona and H. Sandnes, Calculated Budgets for Airborne Acidifying Components in Europe, 1985, 1987, 1988, 1989 and 1990, EMEP MSC-W Report 1/91, Norwegian Meteorological Institute, Oslo, 1991.

${ }^{7}$ S.A. Batterman, Influential receptors in targeted emission control scenarios', Systems Analysis - Modelling - Simulation, Vol 5, 1988, pp 519-532; M. Amann, Using Critical Loads as Basis for Abatement Strategies in Europe, EB.AIR/WG.5/R.7 UN/ECE, Geneva, Switzerland, 1990; M. Amann, G. Klaassen and W. Schöpp, UN/ECE Workshop on Exploring European Sulphur Abatement Strategies (Background Paper), Status Report SR-91-03, International Institute for Applied Systems Analysis, Laxenburg, Austria, 1991

${ }^{8}$ UN-ECE, Review of National Strategies and Policies for the Abatement of Air Pollution, ECE/EB.AIR/R.48, UN Economic Commission for Europe, Geneva, Switzerland, 1990; IEA/ OECD, Coal Information, International Energy Agency, Paris, France, 1990.

${ }^{9}$ M. Amann and L. Sørensen, An Energy Efficiency Scenario for Eastern Europe, Working Paper WP-91-xx (in print), International Institute for Applied Systems Analysis, Laxenburg, Austria, 1991.

${ }^{10} \mathrm{M}$. Amann, Potential and Cost for Control of NO Emissions in Europe, Status report SR-89-01, International Institute for Applied Systems Analysis (IIASA), Laxenburg, Austria, 1989.

${ }^{11}$ Op cit, Ref 2.

${ }^{12} \mathrm{Op}$ cit, Ref 7, Amann et al.

${ }^{13}$ R.W. Shaw, M. Amann and W. Schöpp, 'The regional acidification information and simulation model: a tool to develop emission strategies and assess their effects', Combustion Pollution Reduction, VDI Report 690, Düsseldorf, 1988.

${ }^{14} \mathrm{Op}$ cit, Ref 7, Amann et al. 


\title{
CHP development in Denmark
}

\author{
Role and results
}

\section{H.C. Mortensen and B. Overgaard}

Energy conservation and restructuring towards more energy-efficient technology have been keywords in Danish energy policy in the 1970s and 1980s. This has been reflected especially in domestic heating, where gross energy consumption per square metre has dropped approximately $45 \%$ from the early 1970 s onwards. This drop is directly related to the massive expansion of combined generation of heat and power (CHP) effected in the same period. Consequently, some $30 \%$ of Danish heat requirements are now met by CHP. The intention is to increase this share by a further $7 \%$ over the next decade, resulting in a $37 \%$ share of Denmark's total heat requirements by CHP in the year 2000.

Keywords: Energy conservation; District heating; Combined heat and power (CHP)

This article is concerned with combined heat and power (CHP), in particular dealing with the results achieved in Denmark during the last two decades, and focusing only on CHP production utilized in a district heating network ( $\mathrm{CHP} / \mathrm{DH})$.

However, what is the true sense of 'district heating'? 'District heat' can be defined as 'the heat supply to several buildings or city districts by heating plants', and as 'heat in the low temperature range (up to $200^{\circ} \mathrm{C} / 392^{\circ} \mathrm{F}$ ) which is transported from a central heat supplier over longer distances to the consumer (dwellings, trade, industry)'. In other words - the DH system is a transport system.

The heat supplier can be a heat plant (supplier of heat exclusively) or a heat/power plant. Heat can come from various sources (decoupled waste heat, heat produced by boilers, heat as a combined pro-

H.C. Mortensen is General Manager, and B. Overgaard is Head of Information, Metropolitan Copenhagen Heating Transmission Company, 4 Krumtappen, PO Box 309, DK-2500 Yalby, Denmark. duct of industrial processes, geothermy). The transportation medium is a double pipeline system.

\section{DH - ADVANTAGES AND OBSTACLES}

The use of DH has many advantages - especially in the light of the present-day problems of energy shortages and the environment. An essential characteristic - and one which is also relevant for future energy supply - is its ability to make a swift change to other alternative, cheaper sources of energy. Add to this that DH is a very reliable source of supply, that it enables several different supply systems to be utilized at the same time and - last but not least - it makes increased energy efficiency possible, leading to a decrease in air pollution. This is especially true if production is based on CHP.

So there is no 'shortage' of good arguments. Even so, there is considerable variation from one nation to the other as regards district heating's market penetration. Looking at Figure 1, district heating's share of the total heating market can be seen to vary from being virtually insignificant (the UK and Norway) to over $40 \%$ (Denmark). It is, also, immediately clear that the Nordic countries - Sweden, Finland and Denmark - play an extremely important role in the field of DH (Figure 1).

These differences in district heating's penetration cannot be explained simply by referring to climatic conditions. Norway shares similar climatic conditions with the other Nordic countries, and yet district heating's share of the market is insignificant as part of the country's total consumption. When assessing penetration one therefore has to take both marketrelated and also more subjective and marginal factors into consideration.

These factors include:

- The accessibility of indigenous resources (gas, coal, hydropower, etc).

0301-4215/92/0121198-09 (C) 1992 Butterworth-Heinemann Ltd 